\title{
EMPRESAS PRIVADAS E EDUCAÇÃO PÚBLICA NO BRASIL E NA ARGENTINA
}

\author{
LILIENE XAVIER LUZ
}

\begin{abstract}
RESUMO: Este artigo analisa a participação do empresariado na educação pública básica no Brasil e na Argentina, a partir das reformas dos anos de 1990. Aborda resultados de uma pesquisa realizada nos dois países, elegendo como campo empírico as organizações empresariais com ações na educação pública. Os marcos conceituais estão relacionados às abordagens de autores contemporâneos das áreas de educação e ciências sociais sobre a reforma do Estado e sobre as estratégias e as ações utilizadas pelo poder público para incorporar os múltiplos atores sociais na gestão das políticas educacionais. Os resultados das nossas análises confirmam que os empresários, embora não sejam novos atores, apresentam-se de forma nova e distinta na educação, pela maneira como seus espaços de atuação foram redefinidos e readaptados no processo das reformas recentes, em que o Estado pluraliza os meios de governar, sem deixar de agir como ator central.
\end{abstract}

Palavras-chave: Estado. Políticas educacionais. Empresariado. Brasil. Argentina.

\section{PRIVATE ENTERPRISES AND PUBLIC EDUCATION IN Brazil and Argentina}

\begin{abstract}
This paper analyses the participation of the entrepreneurs in public basic education in Brazil and Argentina after the reforms of the 1990s. It discusses the results of a survey conducted in both countries, whose empirical field was business organizations that provide in public education. It draws on the conceptual frameworks of contemporary authors of the areas of education and social sciences who tackle the reform of the State and the strategies and actions used by public authorities to involve the multiple social actors into the management of the education policies. Our results confirm that, although they are not new actors, entrepreneurs present themselves differently in education due to the way their sphere of action has been re-defined and readapted in the process of the recent reforms, in which the State pluralizes its ways of governing, while continuing to act as the central actor.
\end{abstract}

Key words: State. Education politics. Entrepreneurs. Brazil. Argentina.

Doutora em Educação e professora do Centro de Ciências da Educação da Universidade Estadual do Piauí (UESPI). E-mail: luzlili1@hotmail.com 


\title{
ENTREPRISES PRIVÉES ET ÉDUCATION PUBLIQUE AU Brésil et en Argentine
}

\begin{abstract}
RÉSUMÉ: Cet article analyse la participation du patronat dans l'éducation publique de base au Brésil et en Argentine à partir des réformes des années 1990. Il présente les résultats d'une recherche réalisée dans ces deux pays dont le champ empirique était les organismes d'affaire à l'œuvre dans l'éducation publique. Son cadre conceptuel s'inspire d'auteurs contemporains des champs de l'éducation et des sciences sociales qui étudient la réforme de l'état et les stratégies et actions utilisées par le pouvoir public pour incorporer les multiples acteurs sociaux à la gestion des politiques éducationnelles. Les résultats de ces analyses confirment que les entrepreneurs, bien qu'ils ne soient pas des acteurs nouveaux, se présentent de manière nouvelle et distincte dans l'éducation, par la manière dont leurs sphère d'action a été redéfinie et réadaptée dans le processus des réformes récentes, où l'État pluralise les moyens de gouverner tout en continuant à jouer le premier rôle.
\end{abstract}

Mots-clés: État. Politiques éducationnelles. Patronat. Brésil. Argentine.

\section{Introdução}

participação do empresariado na educação pública tem motivado o debate
e os estudos atuais na área da educação tanto no Brasil como na Argenti-
na, assim como em outros países da América Latina, mais precisamente a partir dos anos de 1990, quando os contornos das reformas implementadas pelo Estado se apresentavam de forma mais concreta no âmbito da educação ${ }^{1}$ e os grupos empresariais ganhavam novo impulso com a inserção de suas organizações dentro do espaço denominado Terceiro Setor, ${ }^{2}$ por meio das parcerias entre o poder público e organizações do setor privado de vários tipos.

Este texto busca contribuir com esse debate, levando em conta a dimensão política que alcançou a educação no conjunto das organizações empresariais e a configuração que tomou, desde os anos de 1990, no interior das reformas e no redimensionamento das relações entre o público e o privado, em cujo eixo se encontra uma mudança nos padrões de gestão e organização das políticas educacionais.

Nossas abordagens resultam de uma pesquisa comparativa entre o Brasil e a Argentina. A pesquisa incluiu fontes primárias como gestores(as) públicos(as) e diretores(as) de organizações empresariais, tendo como instrumentos entrevistas realizadas nos dois países. A definição de alguns critérios permitiu-nos trabalhar com seis organizações: ${ }^{3}$ três do Brasil - Educação para a Responsabilidade Social e o Desenvolvimento Sustentável (uniethos), Centro de Estudos e Pesquisas em Educação, Cultura e Ação Comunitária (CENPEC) e Associação Brasileira dos Fabricantes de Brinquedos (ABRINQ) - e três da Argentina - Fundación Grupo Sophia (FGS), Centro de Implementación de Políticas Públicas para la Equidad y el Crecimiento (CIPPEC) e 
Yacimientos Petrolíferos Fiscales (FYPF). Lançamos mão também de outras fontes primárias, tais como legislação, estatutos e publicações das organizações, devido à ênfase dada pelo poder público à regulamentação da participação das organizações do setor privado e de pessoas voluntárias na gestão pública, o que acabou por propiciar a criação de um conjunto de centros, institutos e fundações de origem empresarial, com a finalidade de desenvolver ações sociais. O período de referência da pesquisa compreende os anos entre 1995 e 2005. Uma pergunta nos instigou no processo de investigação: é possível afirmar se os empresários, a partir da mediação de suas organizações, são, no Brasil e na Argentina, atores educacionais de governo?

O texto está dividido em três tópicos. O primeiro é uma introdução dos aspectos conceituais que norteiam a reflexão sobre as reformas educacionais e sua regulação por meio do Estado. O segundo tópico discute a redefinição das formas de atuação política do setor privado a partir da ampliação do associativismo empresarial e sua influência na educação. $O$ terceiro tópico evidencia as formas como as organizações empresariais estão se inserindo na gestão das políticas educacionais.

\section{Outros atores ou outras formas de governar a educação?}

As mudanças nos processos de regulação social têm estabelecido novas formas de participação do Estado e dos setores privados nas políticas educacionais. Para além dos aspectos normativos que compõem o conjunto das regulamentações das reformas em curso desde a década de 1980, as alterações no modo de regulação social estão concorrendo para a construção de novos ajustamentos na legitimidade do espaço educacional, dando lugar a "estratégias e lógicas de ação de diferentes atores, através da confrontação, negociação e recomposição de objetivos e poderes" (Barroso, 2003, p. 40). Entre esses atores, um vem adquirindo expressão na participação na esfera pública da educação: o empresariado.

A regulação social é aqui entendida como um processo contínuo de busca de ajustamentos econômicos, políticos e sociais, com fins de manter a governabilidade da sociedade, da economia, do Estado; a busca de novas formas de conhecimento e de poder, envolvendo diferentes modos de ação política, espaços, conflitos e atores, não pressupondo mudanças nas estruturas do sistema. Ou seja, para além da desregulação da economia e do social e para além do fato de que a educação estaria fora de qualquer controle por parte do Estado, outras formas de regulação vêm sendo postas em prática, em que as reformas políticas, econômicas e educativas constituem parte desse processo. No caso da educação, uma das características que vem tornando manifesta a alteração nos modos de regulação por parte dos poderes públicos é a criação ou a ampliação de diferentes mecanismos políticos e administrativos, muitas vezes com recursos e dispositivos do mercado (Barroso, 2003), com fins de legitimar 
a governabilidade educativa por meio da participação de outros atores no governo da educação pública.

Essa participação ganhou novos formatos com a crise e reestruturação do capitalismo, das quais uma das consequências foi a redefinição do papel do Estado na gestão das políticas sociais, em particular, das políticas educacionais, ampliando ou criando mecanismos de participação do setor privado na esfera pública da educação. Reformas implementadas em meio ao clima intelectual e ideológico de disseminação de uma visão negativa do Estado e de exaltação das virtudes do mercado e, posteriormente, da "sociedade civil" (Boron, 2003).

De outra parte, as mudanças na atuação do Estado contribuíram também para alterações na atuação do setor privado. Particularmente, o associativismo empresarial ganhou um novo impulso na América Latina como uma das respostas à crise do capitalismo na região, em que o empresariado desempenhou papel importante na reformatação da agenda política e econômica desses países, entre os anos de 1980 e 1990 (Bianchi, 2004b). ${ }^{4}$ Neste período o poder público, através dos seus ministérios, priorizou a interlocução com as organizações do setor privado na gestão das políticas educacionais.

A reconfiguração do Estado e do associativismo empresarial, assim como de outros atores, impulsionou a criação de novos espaços de intermediação entre Estado e sociedade, bem como a emergência de novos modos de regulação das políticas educacionais (Barroso, 2006). Assim, a redefinição do papel do Estado nas políticas sociais e do setor privado ocorre dentro de um contexto dinâmico das distintas regulações sociais, seja no domínio transnacional, nacional ou local (idem, ibid.). Daí a relevância de atentarmos para a relação entre o poder público e o empresariado e para as novas significações atribuídas às políticas educacionais.

Consideramos empresariado o conjunto dos segmentos sociais que ocupam "posições que implicam poder de decisão nas questões estratégicas para a empresa, independente do fato de serem eles detentores ou não da propriedade jurídica do capital cujo comando exercem" (Cruz, 1995, p. 24). Nesse sentido, independem das características que ocupam na diversidade do setor produtivo, tais como esferas de atividades (indústria, comércio ou finanças etc.); origem nacional ou estrangeira do capital; ramos de negócio (brinquedo, bebidas, petróleo etc.), entre outros. A particularidade comum é o "papel que desempenham no movimento de acumulação do capital" (idem, ibid.).

A exemplo do que analisa Marx em $O$ capital, numa sociedade que tem como base o modo de produção capitalista, o empresário desempenha um grande papel na produção de mercadoria, pois esta é considerada a condição primeira da existência de uma empresa. Para além da posição direta que ocupa no movimento de 
acumulação do capital, o empresariado pode ser considerado um burguês que ocupa, no conjunto dos diferentes segmentos sociais, outras funções não econômicas, mas funções jurídicas, políticas e ideológicas (idem, ibid.). Seguindo a explicação de Cruz (op. cit., p. 24), podemos incluir na categoria de empresários "todos aqueles que, embora dispondo de títulos jurídicos sobre uma fração do capital, vivem de renda, não desempenhando qualquer função diretiva em seu processo cíclico de reprodução".

Levando em conta esta diversidade e esta particularidade, nossa opção, portanto, foi por fazer um recorte do setor do empresariado que, por meio de distintas estratégias, participa da definição e da implementação de políticas educacionais. Assim, consideramos como crucial o papel desempenhado na educação pelas organizações criadas no conjunto do associativismo empresarial a partir da década de 1990, pois, diferentemente das empresas, embora não visem lucro, elas agem de forma indireta, ajudando as empresas a obtê-lo, por meio da divulgação de sua imagem. E, além do aspecto econômico, as organizações ligadas aos empresários estão mobilizando um conhecimento que é repassado por meio dos discursos e das representações sobre educação em diferentes espaços, a exemplo da mídia, bem como pelo material produzido para as escolas. Pelas diversas funções que estabelecem com os interesses do capital, tais organizações são aqui denominadas "organizações empresariais", com o intuito de diferenciá-las daquelas de caráter social.

A concepção de atores de governo está relacionada às instâncias que estão administrando, organizando e definindo as políticas educacionais. Ou seja, dentro do papel ativo e central do Estado no desenho das reformas educacionais, há sua reconfiguração, no sentido da transição da noção de um Estado unificado e onipresente para uma forma de governo mais pluralizada (De Marinis, 2008).

Nesse processo, vários atores são incorporados mais diretamente ao "governo da educação", passando a conviver com os atores tradicionais (Estado, instâncias intermediárias, escolas etc.), fazendo com que se redefinam também as formas tradicionais de governar a educação (idem, ibid.). Desse modo, na educação "intervém um complexo conglomerado integrado (como sempre) por elementos da burocracia estatal, mas também por muitos outros atores" (De Marinis, 2008, p. 14), a exemplo das organizações empresariais.

Essa forma de governar a educação vem se fortalecendo com a consolidação das políticas de descentralização no contexto pós-reforma educacional. Embora as análises em torno do tema deem maior ênfase às políticas de municipalização ou provincialização, a depender da estrutura administrativa dos diferentes países, provavelmente o principal legado dessas políticas consista nas distintas dinâmicas que alcançaram, ao longo dos anos, as estruturas de governo e a educação. Além da descentralização para os municípios, estados ou províncias, foram implementadas 
medidas dessa natureza, tendo em vista a autonomia da escola e a participação do mercado, a partir do emprego da noção de responsabilidade social (Krawczyk, 2002). Quando nos referimos à descentralização, estamos considerando essa dimensão ampla, embora com maior ênfase na participação do mercado, devido aos objetivos da pesquisa.

As reformas dos anos de 1990, fortalecidas pelas crises econômicas e acentuadas pelos problemas sociais e educacionais, favoreceram a descentralização para o mercado. Os empresários passaram a ver a educação pública como um espaço onde se pode intervir de diversas formas, como, por exemplo, na formação para o trabalho. Simultaneamente, o poder público incentiva a participação das empresas na educação por meio das parcerias intermediadas com as organizações não governamentais (ONG), os grupos de técnicos, as fundações empresariais, entre outras, pois é principalmente por meio das parcerias que ocorre a interlocução do poder público com os grupos empresariais. Assim, o poder público em nenhum desses dois países tem parceria direta com as empresas; esta ocorre por intermediação, uma vez que os recursos só podem ser repassados para "instituições privadas sem fins lucrativos". Isso não significa dizer que o Estado deixou de se responsabilizar pela educação, mas pressupõe uma estrutura de gestão educacional em que os setores da iniciativa privada passam também a definir políticas educacionais, tendo em vista as mudanças na governabilidade da educação pública.

A governabilidade educativa é aqui entendida como uma problemática da regulação social, pois diz respeito "ao papel do Estado como regulador da ação social no mais amplo sentido" (Hirst \& Thompson, 1998, p. 298) e, particularmente, à compreensão que se tem sobre o papel do Estado e de outros atores no "governo da educação". O que está posto é que os mecanismos de governabilidade da educação se tornam mais complexos quando os poderes públicos ampliam sua associação com outros atores, fazendo com que estes se tornem "atores de governo".

\section{Ampliação do associativismo empresarial na educação}

Assim como o Estado, as organizações de interesse do capital, ${ }^{5}$ tanto no Brasil como na Argentina, redefiniram suas formas de atuação política e vieram ampliando seu universo associativo e sua participação na esfera pública. Isso se deve tanto às estratégias do próprio movimento empresarial como ao favorecimento do Estado e evidencia que, na sua trajetória, os empresários não se comportam somente como agentes do poder econômico, mas também como atores de políticas. Particularmente no Brasil, o empresariado ocupou nitidamente uma posição histórica nas políticas educacionais, mostrando-se muito mais ativo do que na Argentina. Um dos exemplos mais conhecidos é o sistema "S", representado pelo Serviço Nacional de 
Aprendizagem Comercial (sEnAC), pelo Serviço Social do Comércio (SESC), pelo Serviço Nacional de Aprendizagem Industrial (SENAI) e pelo Serviço Social da Indústria (SESI). Isso significa que, mesmo dentro de uma estrutura sindical de representação, a educação tornou-se uma questão-chave para o empresariado brasileiro, pensada no interior de uma política industrial e comercial direcionada para uma determinada política educacional: a de formação técnico-profissional. No caso da Argentina, o empresariado tem uma trajetória de participação menor do que no Brasil, principalmente porque, ao contrário deste país, a Argentina criou um sistema educacional, subsidiando inclusive o setor privado que, em sua maioria, é representado pela Igreja católica. Mas não somente pelo papel que o Estado exerce historicamente na educação; também porque o empresariado na Argentina se mostrou historicamente menos atuante na relação com o Estado do que no Brasil.

Não obstante, nos dois países, o poder público, no contexto das reformas, priorizou a interlocução com o setor privado na formulação e na implementação das políticas educacionais e criou uma série de aparatos legais e administrativos para consolidar essa interlocução com o Estado, principalmente no que favorece às parcerias. Podemos citar como exemplos, no Brasil, a Lei n. 9.608/1998, que dispõe sobre os serviços voluntários; a Lei n. 9.637/1998, que qualifica as entidades como "pessoas jurídicas de direito privado, sem fins lucrativos", e a Lei n. 9.790/1999, que regulamenta a participação do Terceiro Setor na gestão pública; e na Argentina, a Lei n. 24.156/1992, que regulamenta a participação do setor privado na gestão dos serviços públicos, e a Lei n. 20.628/1997, que permite a isenção de impostos às organizações enquadradas como "sem fins lucrativos". O resultado dessa via de mão dupla é que, seja por meio da participação direta, seja intermediados pelas organizações, os empresários, nos dois países, são beneficiados de várias maneiras, quando investem na educação pública. De acordo com informações obtidas durante nossa pesquisa, os benefícios mais citados tanto pelos gestores públicos, como pelos diretores das organizações nos dois países foram: responsabilidades sociais, legais, marketing, incentivos fiscais, retorno pessoal - aspectos intimamente interligados.

As organizações empresariais tornaram-se as principais catalisadoras desses benefícios, pois são elas que fazem com que o empresariado se apresente com maior credibilidade na esfera pública e que esses benefícios se transformem em lucro para os empresários. As organizações, por si mesmas, não têm objetivos de lucro e são, por definição e na prática, "entidades privadas sem fins lucrativos". Porém, elas capitalizam dinheiro para o empresariado, convencendo-o a fazer marketing, já que assim se vende mais; elas ajudam a dar maior legitimidade ao empresariado, quando realizam ações com seu apoio; elas ajudam a fazer repercutir na sociedade o apoio empresarial, quando realizam ações educacionais, canalizando problemas muito localizados como, por exemplo, a formação da mão de obra. Elas são assim 
um caminho indireto para obtenção de lucro. Para além do lucro imediato, ao possibilitarem que os empresários interfiram nas políticas educacionais de forma legitimada na sociedade, as organizações contribuem também para que estes exerçam influência com sua forma de ver o mundo e a educação e que estabeleçam padrões de socialização escolar de acordo com as necessidades e interesses do mercado.

Não obstante, embora com suas especificidades, as organizações no Brasil e na Argentina tiveram, na sua base de fundação, os grupos empresariais ou a influência destes por meio de recursos financeiros. Algumas delas foram criadas dentro das próprias organizações patronais, a exemplo da FYPF, na Argentina, e da Fundação ABRINQ, no Brasil. Suas ações, embora de cunho social, estão muito atreladas ao pensamento dos grupos empresariais que lhes deram origem. No caso da FYPF, as ações educativas estão mais vinculadas às atividades do setor produtivo da empresa (elétrico e petroquímico). Isso ocorre por meio do investimento na geração de novas tecnologias de gás e petróleo, mais do que em outras ações, enquanto a Fundação ABRINQ, por ser ligada aos fabricantes de brinquedos, vinculou suas ações à problemática dos direitos das crianças e adolescentes. Algumas organizações enveredaram mais para o campo das políticas de currículo, avaliação e gestão dos sistemas de ensino e da escola, a exemplo do CENPEC, no Brasil, e do CIPPEC, na Argentina: em ambos, os serviços comumente são encomendados pelo poder público. No caso do Grupo Sophia, na Argentina, as ações aparecem em atividades dispersas, em pesquisas encomendadas pelos empresários e em busca de vinculação com as ações do Estado. E, no caso do uniethos, no Brasil, o trabalho de educação é voltado exclusivamente para a formação da gestão empresarial, mesmo apoiando ações educacionais de outras organizações e manifestando-se nos espaços que lidam com a educação pública. Isso demonstra que as organizações estão participando da gestão das políticas sociais, fortalecendo os princípios de gestão empresarial. Parte-se do pressuposto de que o empresariado tenha um conhecimento que passou a ter valor no âmbito da gestão pública e na sociedade como um todo.

Tanto no Brasil como na Argentina, essas organizações criaram uma estrutura financeira e de recursos humanos, com profissionais de distintas áreas, e articularam-se com o Estado e os demais atores sociais em forma de parceria. Além do poder público, as parcerias envolvem outras empresas, outras fundações, centros de investigação etc., de natureza local, nacional e transnacional. A estrutura das organizações contempla também o voluntariado que se profissionalizou, deixando de ter uma característica individual com base na vontade e na caridade, mas que vem se incorporando como sujeito social dentro da complexa relação de trabalho flexível, em que as "entidades privadas sem fins lucrativos" se tornaram mais um espaço de mercado e, portanto, uma fonte de trabalho.

O crescimento da influência do empresariado nas políticas sociais, particularmente nas políticas educacionais, ocorre sob diferentes ângulos. As organizações 
empresariais criaram uma estrutura de análise de dados que fomenta seus censos; os balanços sociais; as publicações de autores do meio empresarial; a promoção de instituições e os sistemas educacionais; os gestores e os professores, com premiações baseadas em determinados padrões de gestão e de qualidade - algo que vem ocorrendo mais no Brasil do que na Argentina, porém dentro de uma mesma lógica organizacional: intervir na gestão pública.

A influência das organizações empresariais ocorre também por meio do desenvolvimento em pesquisas, em que a principal característica é a elaboração de diagnósticos, seguidos de análises e propostas de intervenção nas políticas, o que comumente resulta em publicações. ${ }^{6}$ Nesse sentido, há um saber que é produzido nas organizações, direcionado para as políticas sociais fora dos centros acadêmicos e do poder público, o que significa dizer que os empresários estão ocupando tanto a posição de organização e gestão do capital como também a de políticas públicas. No caso da Argentina, esta premissa está também relacionada a uma tradição de pesquisa em outros espaços além das universidades, diferentemente do Brasil, onde a pesquisa tradicionalmente se concentrou e se legitimou nas universidades e em alguns centros e institutos.

Por meio das organizações, os empresários movimentam recursos no sentido de difundir um "saber" próprio de suas experiências para o desenvolvimento de ações educacionais. Esse saber vem-se manifestando nas estratégias e ações político-educacionais materializadas na elaboração e na gestão de programas e projetos, no monitoramento e avaliação de resultados etc. As ações idealizadas e realizadas pelas organizações empresariais são comumente disseminadas como eficientes, como econômicas, com impacto na gestão etc., adquirindo assim um determinado "valor social" diante da opinião pública. É também por meio desse conhecimento, respaldado em programas e projetos, que os empresários, intermediados pelas organizações, estão participando das políticas educacionais. Nesse aspecto, a mídia tem sido uma forte aliada do associativismo empresarial, pela divulgação que tem feito das experiências educativas realizadas por pessoas voluntárias e por instituições do setor privado.

Enfim, os empresários estão participando do governo da educação de forma muito diversificada, na medida em que agregaram novos interesses, pulverizaram-se, subdividiram-se e articularam distintas alianças. Contudo, mesmo de forma pluralizada e com ações pulverizadas, as organizações empresariais associam-se, formando grandes organizações para representarem seus interesses. No Brasil, a maioria das organizações que movimenta o mercado da Responsabilidade Social Empresarial (RSE) está vinculada ao Grupo de Institutos, Fundações e Empresas (GIFE), criado em 1995. Algo semelhante vem ocorrendo na Argentina, desde os anos 2000, a exemplo do Instituto Argentino de Responsabilidade Social (IARSE), criado em 2002, com a "missão de promover e difundir o conceito de responsabilidade social". 
Esse associativismo apresenta-se assim de forma cada vez mais complexa, seja somando as organizações que já existem, sobrepondo-as ou criando outras que agregam novos interesses. Além daquelas vinculadas a uma empresa em particular, uma mesma organização pode aglutinar outras de caráter empresarial. As empresas podem ou não estar associadas a um mesmo ramo da cadeia produtiva e comercialização, assim como podem desenvolver ações por iniciativas próprias de suas entidades ou também em parceria com outros atores, não necessariamente dos setores econômicos; ou, ainda, desenvolver ações com o poder público.

Embora haja controvérsias, o empresariado vem-se mostrando cada vez mais forte e mais ativo na relação com o poder público, ocupando, muitas vezes, o espaço da gestão pública, num processo em que as organizações têm desempenhado um papel fundamental.

Nesse sentido, alguns traços - ordenados também a partir de entrevistas durante a pesquisa - podem ser elencados, para fins de caracterizar no geral essas organizações:

1. As organizações estão atuando com visão de gestão pública, por meio da oferta de serviços e da elaboração de demandas para o Estado. No caso do Brasil, há uma maior tendência à indução para que o poder público implemente as políticas, assim como algumas das organizações agem diretamente junto a este poder. Na Argentina, ainda que haja indução e ação direta, prevalece mais o trabalho de assessoria.

2. Diferentemente da filantropia tradicional, que estava orientada para a assistência, as organizações estão mais voltadas para o "social". No entanto, no caso do Brasil, a filantropia foi mais presente do que na Argentina, por ter esta uma tradição de educação laica e promovida pelo Estado e por haver, naquele país, uma histórica indefinição do Estado na criação de um sistema educacional. Enquanto as organizações, na Argentina, estão se mostrando mais preocupadas com a crise social (crescimento da pobreza, desemprego, violência) e, a partir desta, com a situação educacional, talvez porque as desigualdades sociais estejam traduzindo o binômio crise e reforma, no Brasil há uma preocupação maior com os indicadores educacionais, pois com a reforma reiniciase um debate sobre a possibilidade de universalização da educação básica.

3. No geral, em ambos os países, anteriormente, as organizações respondiam apenas a demandas externas e suas ações eram mais dispersas; mas, após a regulamentação por parte do poder público, suas ações estão mais focalizadas, devido, principalmente, à possibilidade de criação 
de seus próprios programas e projetos e à participação em programas e projetos do Estado.

4. Algo comum ocorre também em relação a uma preocupação atual, por parte das organizações, com o monitoramento e a avaliação de impacto das ações, talvez devido ao fato da gestão privada agir em função da eficácia e dos resultados imediatos.

5. No que diz respeito às ações, estas eram definidas, na maioria das vezes, unilateralmente e baseadas em critérios individuais de iniciativa de algum gerente ou diretor de empresa, ao passo que, atualmente, as organizações agem em forma de corresponsabilidade de projetos e por meio de alianças e estratégias institucionais.

6. Como as iniciativas eram individuais, os recursos aportados eram basicamente dinheiro ou bens materiais e davam-se mais no nível gerencial, ao passo que, atualmente, envolvem múltiplos recursos e atores.

As características aqui apresentadas evidenciam que as organizações empresariais passaram por um processo de redefinição para sua adaptação às novas estruturas do capitalismo, arregimentadas por uma ordenação institucional por parte do Estado. Isso evidencia que mesmo a obtenção do lucro só é possível se estiver associada a outros fatores que transcendem o aspecto econômico. Nesse processo, os empresários utilizam a educação como espaço de participação no Estado, como forma de obtenção de lucro e de repassar um saber que os legitima na sociedade.

Essas mudanças vão aparecendo de diversos modos, pois o que preponderava em períodos anteriores era uma tradição filantrópica, que consagrou muitas iniciativas na educação com característica de benevolência, vinculadas a iniciativas individuais ou a instituições religiosas de vários tipos, sobretudo no Brasil, onde a presença do Estado na educação é historicamente menor do que na Argentina. Neste momento, as organizações afastaram-se mais dessa ideologia da meritocracia, assumindo uma racionalidade pautada na eficácia, na eficiência e na gestão descentralizada, para que os meios cheguem aos fins a partir de determinados resultados alcançados, conforme metas anteriormente traçadas. É assim que as organizações empresariais mostram uma feição comum nos dois países: sua lógica de funcionamento é interna à gestão das ações governamentais.

\section{O lugar do empresariado na gestão das políticas educacionais}

Na Argentina, a participação do empresariado nas políticas educacionais teve como antecedentes o avanço da "reforma da educação nacional, que se iniciou em 1992 com o processo de descentralização definitiva do sistema e se instituiu 
legalmente com a Lei Federal de Educação ditada em 1993" (Tiramonti \& Suasnabar, 2001, p. 66) e as crises econômicas e sociais no início dos anos 2000, quando o empresariado ressurgiu, após um longo período de desindustrialização, mostrando-se mais preocupado com as questões sociais e encontrando no espaço descentralizado um nicho de aproximação com o "poder local". No Brasil, porém, as reformas e as crises não são parâmetros para a inserção do empresariado na educação, mas para a ampliação de seus espaços de atuação, bem como de aproximação com os municípios.

Independentemente da trajetória do Estado e do setor privado nos dois países, as mudanças nos processos de regulação social geradas pela crise do modelo de acumulação do capitalismo, baseado no fordismo keynesiano, colocaram em xeque o papel do Estado como ator central de regulação da economia e da gestão das políticas sociais. O principal argumento era de que a crise havia sido gerada pelo Estado, por ter este desencadeado um aumento do imposto fiscal, não conseguindo mais manter o equilíbrio da economia e administrar as políticas sociais.

As mudanças nos processos de regulação social estavam vinculadas ao ato de governar como não exclusivo do Estado, mas em parceria com outros atores. Inicialmente, disseminou-se uma imagem negativa do Estado e uma supervalorização do mercado e da gestão privada. Nesse processo, as racionalidades políticas e os programas de governo foram sendo alterados desde os anos de 1980, em razão da adequação às reformas liberais, tendo ficado, num primeiro momento, mais próximos da desregulação por parte do Estado.

A Argentina foi um dos países que experimentou as reformas na sua feição mais privatista. No processo de acomodação do capitalismo, tendo em vista as crises nas suas próprias racionalidades políticas, outras vertentes do liberalismo foram surgindo, contemplando elementos das racionalidades políticas anteriores. A tendência mais recente é a chamada Terceira Via, por onde os governos da década de 1990 em diante - a exemplo do Brasil e agora da Argentina - redimensionaram muitas das ações governamentais no âmbito das relações entre público e privado. Entre os parâmetros de redefinição do papel do Estado na governabilidade da gestão pública, encontra-se o que ficou definido como público não estatal, por meio do qual as organizações do setor privado são remodeladas e regulamentadas no plano estatal.

Assim, em lugar de uma simples retração do Estado, verifica-se a complexidade do emaranhado de relações entre o público e o privado, dando lugar à configuração de atores sociais e políticos. Nesta complexidade, recodifica-se o papel do Estado e delineiam-se os papéis de suas instituições anexas:

Organismos estatais, subestatais e supraestatais, oNGs, organismos internacionais financeiros e humanitários, agências de consultoria, think tanks, conglomerados de meios de comunicação, lobbies, partidos políticos, organizações sociais e comunitárias de diversos 
tipos (...) passam a constituir uma densa rede em cujo marco se planificam, desenham, executam e avaliam políticas, planos e programas de governo (...). Esquematicamente: o Estado "economiza", "racionaliza", "otimiza" cada vez mais suas energias, se aproveitando, se servindo e apelando para a energia mesmo dos governados, para governá-los. (De Marinis, 2005, p. 20)

No caso particular do empresariado, este expandiu seu associativismo, principalmente por meio da criação de novas organizações e da renovação de entidades já existentes (Bianchi, 2004a). Nesse complexo associativo, a legislação que regulamentou a participação das organizações do setor privado e de pessoas voluntárias na gestão pública acabou por propiciar a criação de um conjunto de centros, institutos e fundações de origem empresarial, com a finalidade de desenvolver ações sociais.

Essas organizações ampliaram o universo das relações empresariais, sobretudo no campo das políticas sociais, tanto com as organizações da estrutura tradicional de representação do empresariado (sindicatos e associações patronais), quanto com os atores da sociedade civil e com o poder público, tornando mais complexas as relações entre público e privado.

A educação escolar tornou-se um campo de atuação do empresariado intermediado por suas organizações, servindo-se de argumentos seculares como a "importância da educação para o desenvolvimento e para a formação de mão de obra qualificada". Nesse universo encontra-se um amplo leque de ações que envolvem os aspectos pedagógicos, as relações comunitárias e as políticas educacionais mais amplas. As organizações empresariais tornaram-se também um dos "mediadores sociais" incentivados pelo poder público para atuar nas atividades curriculares, extracurriculares, na ocupação do tempo livre, para compensar o déficit das atividades educativas ou das políticas compensatórias (Barroso, 2005).

As diferenças entre o Brasil e a Argentina, no que concerne à participação do empresariado na esfera pública de educação, devem-se principalmente à maneira como as organizações atuam como agentes de governo. Muito embora, como um todo, participem da educação de forma ao mesmo tempo focalizada e pluralizada, elas agem direta e indiretamente nas políticas educacionais. No Brasil, essa forma de participação tem uma característica mais indutiva, no sentido de que a maioria das organizações está influenciando politicamente os programas de governo para que o poder público implemente ações socioeducacionais. Isso se verifica principalmente pela criação de vários mecanismos de indução à implementação de políticas públicas e de seu monitoramento e avaliação, como é o caso dos selos da Fundação ABRINQ. Mesmo o CENPEC, que é uma organização bastante eclética, inclusive agindo diretamente na escola, tem feito com que alguns dos seus programas se tornem políticas públicas. 
Não obstante as diferenças com que as organizações empresariais se inserem no universo educacional, são vários os motivos pelos quais os empresários, no Brasil e na Argentina, justificam seu interesse pela educação pública, tais como marketing, responsabilidade social, benefícios fiscais, colaboração com o Estado, formação para o trabalho etc. Ao mesmo tempo, afirmam a importância do papel do Estado na implementação e na regulação das políticas educacionais.

No entanto, a nosso ver, a participação do empresariado na educação, tal como vem se apresentando atualmente, responde ao movimento das reformas, em que o Estado redefiniu seus modos de atuação na sua relação com a sociedade e, nesse processo, o poder público priorizou a interlocução com o setor privado na gestão das políticas educacionais.

Nesse sentido, podemos considerar que os empresários são, no Brasil e na Argentina, atores educacionais de governo? São e não são novos atores, apresentam-se de forma distinta no governo da educação, pela maneira como seus espaços de atuação foram redefinidos e readaptados no processo das reformas recentes, em que o Estado pluraliza os meios de governar, sem deixar de atuar como agente central.

\section{Notas}

1. Afirmação baseada em um levantamento sobre o tema.

2. Embora alguns autores ressaltem a forma imprecisa com que tem sido usado o termo Terceiro Setor, este é comumente definido como o conjunto das organizações da sociedade civil de direito privado sem fins lucrativos, com interesses públicos. Para um melhor entendimento sobre a definição do Terceiro Setor, seu significado e o debate que este tema vem suscitando, bem como as diferentes abordagens em torno dele, podem-se consultar autores como Fernandes (1994) e Montaño (2002).

3. Os critérios utilizados foram: 1 - as organizações que tiveram os grupos empresariais como fundadores ou como intermediários para sua criação; 2 - a relevância que determinadas organizações adquiriram no universo da educação a partir da década de 1990; 3 - a abrangência das organizações em relação tanto à presença nacional em cada um dos países, quanto ao fato de contemplar uma rede de associados e parceiros dentro e fora do poder público em ações educativas.

4. A categoria "associativismo empresarial" é utilizada neste trabalho a partir dos estudos de Bianchi (2004a, 2004b), no sentido de delimitar a forma como os empresários organizam suas estruturas de representação, cuja característica é a criação de associações distintas, formando uma estrutura paralela e sobreposta de organização, que vai conformando um complexo associativo e um intricado de relações.

5. Segundo Offe (1984), ao contrário do trabalho, que tem somente uma forma de organização para defender seus interesses, no caso o sindicato, o capital tem sob seu comando três diferentes formas de ação coletiva: a própria firma, a cooperação informal e a associação dos empregadores ou de empresas.

6. Ver, por exemplo, a publicação do Banco Itaú em parceria com o UNICEF, intitulada “Educação para a inclusão: a parceria Itaú-UNICEF". 


\section{Referências}

ARGENTINA. Ley 20.628, Ley de Impuesto a las Ganancias. Buenos Aires, 11 de julio de 1997.

ARGENTINA. Ley 24.156, Administración financiera y de los sistemas de control del sector público nacional. Buenos Aires, 30 de setiembre de 1992.

BARROSO, J. Regulação e desregulação nas políticas educativas: tendências emergentes em estudos de educação comparada. Lisboa: ASA, 2003.

BARROSO, J. O Estado, a educação e a regulação das políticas educativas. Educação E Sociedade, Campinas, v. 26, n. 92, p. 725-751, out. 2005.

BARROSO, J. A regulação das políticas públicas de educação: espaços, dinâmicas e actores. Lisboa: Educa, 2006.

BIANCHI, Á. Estado e empresários na América Latina (1980-2000). Antropolítica, Niterói, v. 16, n. 16, p. 101-122, 2004a.

BIANCHI, Á. O Ministério dos Industriais: a Federação das Indústrias do Estado de São Paulo na crise das décadas de 1980 e 1990. 2004b. Tese (Doutorado) - Instituto de Ciências Humanas da Universidade Estadual de Campinas, Campinas.

BORON, A. Estado, capitalismo y democracia em América Latina. Buenos Aires: clacso, 2003.

BRASIL. Lei n. 9.637, de 15 de maio de 1998. Dispõe sobre a qualificação de entidades como organizações sociais, a criação do Programa Nacional de Publicização, a extinção dos órgãos e entidades que menciona e a absorção de suas atividades por organizações sociais, e dá outras providências. Diário Oficial da União, Brasília, DF, 1998.

BRASIL. Lei n. 9.790, de 23 de março de 1999. Dispõe sobre a qualificação de pessoas jurídicas de direito privado, sem fins lucrativos, como Organizações da Sociedade Civil de Interesse Público, institui e disciplina o Termo de Parceria, e dá outras providências. Diário Oficial da União, Brasília, DF, 1999.

BRASIL. Lei n. 9.608, de 18 de fevereiro de 1998. Dispõe sobre o serviço voluntário e dá outras providências. Diário Oficial da União, Brasília, DF, 1998.

CRUZ, S.C.V. Empresariado e Estado na transição brasileira: um estudo sobre a economia política do autoritarismo (1974-1977). Campinas: Editora da UNICAMP; São Paulo: FAPESP, 1995.

DE MARINIS, P. Comunidad, globalización y educación: algunas reflexiones acerca de la “desconversión de lo social”. Argentina: uba; CONICET, 2008. (Digital). 
DE MARINIS, P. 16 comentarios sobre la(s) sociología(s) y la(s) comunidade(es). Papeles del CEIC, Madrid, n. 15, ene. 2005. Disponible en: <http://www.ehu.es/ceIc/ Papeles/15.pdf>.

ITAÚ/UNICEF. Educação para a inclusão: a parceria Itaú-UNICEF. Brasil: Itaú; UNICEF, 2002.

FERNANDES, R.C. Privado, porém público: o Terceiro Setor na América Latina. Rio de Janeiro: Relume-Dumará, 1994.

HIRST, P.; THOMPSON, G. Globalização em questão: a economia internacional e as possibilidades de governabilidade. Petrópolis: Vozes, 1998.

KRAWCZYK, N.R. Em busca de uma nova governabilidade na educação. In: OliveIRA, D.A.; Rosar, M.F.F. (Org.). Política e gestão da educação. Belo Horizonte: Autêntica, 2002. p. 59-72.

MARX, K. O capital. Crítica da economia política. Rio de Janeiro: Bertrand Brasil, 1988. (Livro primeiro, parte primeira).

MONTAÑO, C. Terceiro Setor e questão social: crítica ao padrão emergente de intervenção social. São Paulo: Cortez, 2002.

OFFE, C. Problemas estruturais do Estado capitalista. Rio de Janeiro: Tempo Brasileiro, 1984.

TIRAMONTI, G.; SUASNABAR, C. La reforma educativa nacional. Em busca de uma interpretación. In: Tiramonti, G. Modernización educativa de los '90. ¿El fin de la ilusión emancipadora?. Buenos Aires: FLACso; Temas Grupo Editorial, 2001. p. 49-70.

Recebido em março de 2009.

Aprovado em janeiro de 2010. 